PROPRIEDADES DE SISTEMAS DE CLASSIFICADORES NUMÉRICOS

EM ALGUMAS LÍNGUAS DO MUNDO

GLÁUCIA VIEIRA CÂNDIDO*

RESUMO

Com o apoio da literatura específica, este texto apresenta, a título exclusivo de revisão, uma breve descrição de alguns aspectos de um tipo muito comum de sistema de classificação: os classificadores numéricos. Nesse sentido, são focalizadas algumas propriedades básicas desses classificadores relacionadas às tipologias lingüísticas e, ainda, descritas as referidas propriedades mais detalhadamente por meio de exemplos coletados em línguas como o Japonês, o Thaí e, em especial, algumas línguas indígenas como o Yagua (Peba-Yagua), o Palikur (Aruák), línguas Chibchan, entre outras.

PALAVRAS-CHAVE: Lingüística, gramática, sistema de classificação, classificadores numéricos.

INTRODUÇão

Um sistema de classificadores, segundo Grinevald (2000), é um conjunto de unidades enquadrado nos vários tipos de sistema de classificação nominal. Ou seja, os classificadores seriam uma subclassificação dos diversos tipos de sistemas classificatórios lingüísticos existentes, sendo os mais comuns os numéricos, os nominais, os genitivos e os verbais.

Lembrando que o tema em questão não é novidade, haja vista diversos estudos como os de Allan (1977), Denny (1979), Aikhenvald (2000), Grinevald (2000), entre outros, chamamos especial atenção para a revisão de alguns aspectos sobre certas propriedades, especificamente, morfológicas, sintáticas e semânticas de um desses tipos de classifica-

* Professora da Universidade Estadual de Goiás. Doutoranda em Lingüística na Unicamp. E-mail: glaucia.v@uol.com.br 
dores: os numéricos. Esses classificadores são assim designados por serem formas usadas para categorizar nomes que se realizam exclusivamente nos contextos de quantificação.

Nesses termos, no presente estudo apresentaremos algumas notações preliminares acerca de propriedades básicas dos classificadores numéricos relacionadas às tipologias lingüísticas. Na seqüência, descreveremos as referidas propriedades mais detalhadamente por meio de exemplos coletados em línguas como o Japonês, o Thaí e, em especial, algumas línguas indígenas como o Yagua (Peba-Yagua), o Palikur (Aruák), línguas Chibchan, entre outras. Finalmente, abriremos espaço para alguns questionamentos sobre a natureza dos classificadores numéricos em algumas línguas.

\section{NOTAÇÕES PRELIMINARES}

Diversos estudos descritivos têm mostrado uma variedade de sistemas de classificação nas línguas do mundo. Contudo, tal diversidade nem sempre é claramente percebida em algumas descrições lingüísticas e isso se deve, muitas vezes, a questões terminológicas. Afinal, o que estamos entendendo aqui como sistemas de classificação, classificadores, entre outros termos e expressões? Embora a categorização dos sistemas de classificação esteja se mostrando bastante diversificada de autor para autor, tentaremos nessas notações preliminares explicitar nossa compreensão da terminologia doravante utilizada. ${ }^{1}$

Segundo Grinevald (2000), classificadores são elementos constitutivos de um conjunto que se encontra entre os muitos tipos de sistema de classificação nominal. Assim, um sistema de classificadores seria apenas uma espécie de subclassificação dos vários tipos de sistemas classificatórios. Outros tipos de sistemas de classificação nominal são, por exemplo, o sistema de gênero e o de classe nominal. ${ }^{2}$

Segundo Allan (1977), talvez todas a línguas do mundo tenham classificadores. Isso porque, para esse autor, os classificadores podem 
ser definidos com base em dois critérios: eles ocorrem como morfemas nas estruturas superficiais das línguas sob condições específicas; eles têm significação imputada na entidade a que o nome associado se refere. No Inglês, por exemplo, os possessivos correspondem exatamente aos lexemas que na língua Thaí tem sido convencionalmente chamados de classificadores. Claro é, entretanto, que algumas línguas fazem mais uso de classificadores do que outras. Como diz Allan (1977), o Thaí é uma dessas línguas, enquanto o Inglês, não.

Ainda de acordo com Allan (1977), há quatro tipo de línguas que possuem classificadores: aquelas que têm classificadores numéricos, as que têm classificadores de concordância, as com classificadores predicativos e, enfim, aquelas que têm classificadores intra-locativos. Essa divisão se deve à quantidade de classificadores que mais ocorrem numa língua. Algumas delas têm somente um tipo de sistema de classificadores, como é o caso do Gavião (Tupi) que tem apenas os numéricos, enquanto outras podem combinar mais de um sistema, como é o caso do Yagua (Peba-Yagua) que os combina com aqueles de concordância (Derbyshire \& Payne, 1990).

Quanto aos classificadores propriamente ditos, quatro tipos são mais freqüentes: os numéricos, os nominais, os genitivos e os verbais. Todos são comumente definidos, segundo Denny (1976), com base no fato de as categorias marcadas por classificadores (de qualquer tipo) serem um reflexo das interações dos falantes com os objetos e os ambientes em que estão envolvidos. Essas interações podem ser: a) social, quando categorizam seres humanos quanto a status social, sexo, idade e, às vezes, distinguindo-os de divindades e outras entidades dotadas de poderes especiais; b) físicas, se categorizam objetos da natureza em virtude de sua essência/matéria ou sua forma e consistência; c) funcional, quando categorizam itens por seu uso, tais como comida ou transporte, por exemplo. Passemos agora à descrição dos classificadores numéricos, o objeto de estudo deste trabalho. 


\section{OS CLASSIFICADORES NUMÉRICOS}

Os sistemas de classificadores numéricos ocorrem em muitas línguas do mundo. Aliás, de acordo com Aikhenvald (2000), provavelmente é o tipo mais comum de sistema de classificação nominal, depois das classes de nomes e de gêneros. Esses classificadores constituem morfemas que em uma combinação com numerais modificam nomes e, às vezes, têm a função de enumerar também.

Como já demonstrado por alguns estudiosos, os sistemas de classificadores numéricos podem diferir muito quanto a sua estrutura. Do ponto de vista morfossintático, geralmente figuram contíguos a numerais em sintagmas nominais de conteúdo numérico e expressões que indicam quantidade. Normalmente, eles não necessitam aparecer exatamente em qualquer componente fora do sintagma nominal numérico e, por isso, não é necessário haver concordância do classificador numérico com o nome e outro componente.

Além dessas propriedades, os classificadores numéricos comumente são escolhidos a partir de critérios semânticos, os quais variam bastante, envolvendo normalmente as categorias: material (animado $x$ inanimado), consistência (flexível x rígido), localização (configuração, posição), quantidade (singular, dual, plural etc.), forma (longo, arredondado, plano), tamanho (grande, médio, pequeno), entre outros. Além disso, algumas vezes um classificador "genérico" pode ser usado com qualquer - ou quase qualquer - nome, substituindo outros classificadores mais específicos.

Outro aspecto relevante é o fato de sistemas de classificadores numéricos diferirem na extensão em que são gramaticalizados e poderem ser também uma classe lexical aberta. Assim, em uma língua com um grande número de classificadores numéricos, o modo como são freqüentemente usados varia de falante para falante, dependendo de seu status social e de sua habilidade, como atesta Adams (1989, apud AikhenVALD, 2000). Ademais, em algumas línguas que possuem sistema 
de classificadores numéricos, nem todo nome pode ser associado a eles. Alguns nomes podem não possuir nenhum classificador; outros podem ter escolhas entre várias alternativas deles, dependendo de qual propriedade do nome está em foco.

Finalmente, lembremos que tais propriedades e categorias dos classificadores numéricos estão intimamente relacionadas com as interações dos falantes com os objetos e ambientes em que estão envolvidos. Isto é, às vezes, o que para o falante de uma língua parece ter o formato circular, para o falante de uma outra língua já parece mais oval, por exemplo. Logicamente essa é uma questão relativa a pontos de vista culturais, algo que nos estudos sobre classificadores é sempre muito relevante.

Como não poderia ser diferente, a presença de classificadores numéricos em uma língua é tradicionalmente associada a várias propriedades tipológicas, tal como veremos no tópico seguinte.

\section{Tipologias lingüísticas e tipos de classificadores numéricos}

Como destacamos no item anterior, freqüentemente, os classificadores numéricos são lexemas independentes, embora possam ser também afixados a numerais. Esses dois tipos de classificadores compartilham quase todas as propriedades, com exceção do fato de que em línguas isolantes, eles são geralmente itens independentes, como podemos observar no Mandarim Chinês (DENNIS, 1976):

\begin{tabular}{|c|c|}
\hline 1. sãn & zhĩ \\
\hline três & class: ${ }^{3}$ objetos longos \\
\hline
\end{tabular}

Além das línguas isolantes, é comum encontrarmos classificadores numéricos em línguas tipologicamente aglutinantes, como o japonês e algumas línguas do Níger-Congo; também em polissintéticas, a exemplo das amazônicas das terras baixas; e, ainda, em línguas fusionantes, como o Índico e o Sul Dravidiano.

Duas espécies de sistemas numéricos são possíveis de ocorrer nas tipologias lingüísticas supramencionadas. Primeiramente, é possível 
perceber em algumas línguas uma vasta classe de numerais com que se indica tanto quanto for o número exigido. Línguas isolantes como as do Leste e Sudeste asiático, o Dravidiano e algumas turcas aglutinantes são desse tipo e costumam apresentar grande quantidade de classificadores numéricos.

Outras línguas, entretanto, têm pouquíssimos numerais, geralmente restritos a um, dois, talvez três e muitos, como ocorre em línguas da Nova Guiné, na maioria da Austrália e em muitas línguas sul-americanas indígenas. Outras línguas podem ter até cinco, como é o caso do Cabécar (Chibcha), falado na América Central, por exemplo. Nesta língua, os numerais correspondentes a formas simples compreendem as quantidades de "um a cinco". Peña (1989) assinala a esse respeito que as formas para "cinco" apresentam uma baixíssima freqüência de uso. Segundo esse autor, os falantes preferem usar a expressão sá jula que significa "nossa mão", a qual também é utilizada para constituir as formas quantificadoras a partir de seis unidades. Assim, para indicar quantidades de "seis" a "nove", os falantes utilizam a expressão sá jula seguida da partícula $k i$ (referente à conjunção aditiva mais) e o numeral correspondente à classe do objeto quantificado, como vemos em (2), abaixo:

$\begin{array}{lllll}\text { 2. busí sá jula } & \text { kí } & \text { ból } & \text { 'sete garotas' } \\ \text { garota } & \text { nossa mão } & \text { mais } & \text { dois (class-humano) } & \end{array}$

Quando os numerais ultrapassam "nove", indo de 10 a 20, o procedimento, no Cabécar, consiste na quantificação de sá jula seguida da expressão bótkö, que significa "nossa mão duas vezes", ou seja, uma cadeia formada pela seqüência constituída por 10, a partícula $k i$ e o numeral correspondente à classe do objeto quantificado, como vemos em (3), abaixo:
3. móglö sa jula bótkö kí mañátabö 'treze rifles' rifle nossa mão dois mais três
(class-coisas planas) (class-coisas estendidas)


Línguas como essa costumam se apoiar em alguma forma de indicação dêitica para números mais significativos ou, então, emprestam numerais mais altos de línguas próximas. O Cabécar busca esse apoio no Espanhol ou, ainda, no próprio dialeto por meio do emprego do quantificador indefinido taí, indicando a numeração superior.

Ainda com respeito às línguas com um número reduzido de numerais, devemos dizer que a tendência é que elas não tenham classificadores numéricos. Certamente, existem exceções, como é o caso das línguas da família Aruák que, apesar de terem de dois a três numerais, grande parte tem classificadores numéricos, conforme veremos ainda neste estudo com exemplos do Palikur.

Outra questão importante sobre classificadores se observa nas línguas que não contam com numerais em um sentido restrito, isto é, naquelas em que não são usados numerais para contar. Segundo Dixon (1980, apud AikHENVALD, 2000), em línguas australianas que apresentam formas para um, dois, talvez três, estas são, geralmente, de composição/ combinação. Alguns estudiosos sugerem, porém, que às vezes tais formas não são de fato numéricas, mas, sim, determinantes indefinidos, como os pronomes um e algum em Inglês. Cabe lembrar, ainda, que se os numerais pertencem a uma classe majoritária de palavras, isto pode responder parcialmente pela ausência de classificadores numéricos em línguas australianas, nas quais os numerais são distribuídos entre as classes dos adjetivos e substantivos. O Gurr-goni, por exemplo, só tem dois numerais: um é um adjetivo, enquanto dois é um substantivo e $u m$, como adjetivo, concorda com a classe dos substantivos.

Outro ponto relevante é que em línguas com sistemas numéricos mais complexos, o uso de classificadores pode depender do numeral. Assim, os classificadores poderão restringir-se provavelmente ao uso com numerais menores. Em muitas línguas, aliás, eles são obrigatórios com números pequenos e opcionais com os grandes. Por exemplo, em Mianngkabau (Austronesiana), os classificadores numéricos são obrigatórios com numerais entre um e três e opcionais com outros; no 
Burmese, não ocorrem em múltiplos de dez; já em tailandês, não são usados com numerais maiores como 1000, a menos que a individualização seja expressa. Tal como veremos ainda neste estudo, a omissão de um classificador pode estar relacionada à organização semântica do sistema lingüístico.

Uma melhor descrição da distribuição de classificadores numéricos nas diversas tipologias lingüísticas do mundo pode ser vista em Aikhenvald (2000, p. 121). Passaremos a seguir a um detalhamento das propriedades já referenciadas aqui.

Propriedades gramaticais e semânticas dos classificadores numéricos

Do ponto de vista morfológico e sintático, os classificadores numéricos podem ser: a) lexemas independentes; b) afixos ou clíticos ligados a (ou fundidos com) numerais; c) afixos ou clíticos ligados a (ou fundidos com) o nome principal, o que, aliás, é extremamente raro.

Antes de focalizarmos cada um desses casos, observaremos brevemente a sintaxe de colocação dos classificadores numéricos nas línguas. Notoriamente, parâmetros de variação nas construções de classificadores numéricos incluem a ordem e as relações de constituições nas construções de classificadores. Certamente, a ordem constituinte costuma depender de regras sintáticas gerais de cada língua e, a propósito disso, Greenberg (1972, apud AIKHENVALD, 2000) estabeleceu quatro possíveis ordens constituintes para ocorrência de classificadores numéricos: a) [Num-Class]-N, que verificamos, por exemplo, no Assamese; b) N[Num-Class], que ocorre no Thai e no Mal, línguas do Leste e Sudeste asiático, respectivamente; c) [Class-Num]-N, que observamos no Ibibio (Niger-Congo); d) N-[Class-Num], o que, possivelmente, notamos no Bodo (Sino-Tibetano). Dentre essas ordens, as duas primeiras são as mais freqüentes.

No esquema de construções apontadas por Greenberg, é possível visualizar uma particularidade interessante: em todas as construções vê- 
se que numerais e classificadores estão sempre em posição de adjacência. Contudo, não é possível distinguir ali classificadores como lexemas independentes daqueles que figuram como afixos, embora isso não seja relevante aqui. Nos propósitos iniciais deste tópico, voltemos à descrição das possíveis realizações morfossintáticas dos classificadores numéricos.

Os classificadores numéricos como lexemas independentes incluem geralmente classes lexicais semi-abertas de morfemas e são encontrados em línguas isolantes, como ilustra o Mal (AIKHENVALD, 2000):

4. Pən ?ui Pooi phe? Iв? 'Eu tenho três potes' $\mathrm{Eu}$ tenho pote três class-arredondado-objeto

5./ən /ui khwan thiat phoon loy 'Eu tenho quatro crianças' $\mathrm{Eu}$ tenho crianças quatro class-humano

Como observamos, o exemplo (4) ilustra um classificador que se refere à forma, enquanto o (5), um classificador baseado nas características humano/animado e ambos figuram pospostos ao nome, de forma independente ou livre.

Línguas fusionantes também apresentam classificadores numéricos como lexemas independentes, como o Assamese, do subgrupo Magadhan do Indo-Aryano (BARz \& Diller, 1985, apud Aikhenvald, 2000) cujos classificadores podem combinar simultaneamente referência a sexo, animacidade e cortesia (educação), tal como nos exemplos:
6. tini zon xokhi 'Três amigos (respeitosamente)'
três class-humano-macho amigo
7. tini zoni sowali 'Três garotas (desrespeitosamente)' três class-fem-desrespeitosamente garota
8. tini' goraki mohila 'Três mulheres (respeitosamente)'
três class-humano-respeitosamente mulher
Como podemos notar, zon é usado para macho-humano em nível normal de respeito; zoni, para animal-feminino e fêmea-humana em nível 
desrespeitoso e graki, para humanos de ambos os sexos em nível respeitoso. Todos os exemplos mostram classificadores como formas independentes.

Outros exemplos de formas as quais podem ser chamadas de classificadores independentes, observamos no Thai. Segundo Haas (1964), essas palavras são usadas como quantificadores, indicadores ou adjetivos, nunca acompanhando nomes e podem às vezes denotar período/ tempo como no caso de wan para 'dia', khy.n, 'noite' e pi. para 'ano'. Interessante, ainda, é observar que quando tais termos precisam ser quantificados, obrigatoriamente o quantificador os precede em forma de afixo, por exemplo:

$\begin{array}{ll}\begin{array}{c}\text { 9. să.m-wan } \\ \text { três-dia }\end{array} & \text { 'três dias' } \\ \begin{array}{c}\text { 10. nyy-pi } \\ \text { um-ano }\end{array} & \text { 'um ano' }\end{array}$

Em línguas que usam repetidores, ou seja, em que o próprio objeto especificado ou parte dele é usado como um numerador, os classificadores numéricos podem ser considerados uma classe aberta. Vale lembrar que, de acordo com Burling (1965, apud AikHENVALD, 2000) os repetidores podem ser considerados classificadores-próprios, auto-classificadores, classificadores-ecoantes ou, ainda, classificadores idênticos, e é por isso que os classificadores ultrapassam os limites entre as classes fechadas e as de palavras abertas, como observamos no Thai (Hundius \& KöLVER, 1983):

$\begin{array}{clll}\begin{array}{c}\text { 11. prathêet } \\ \text { terra }\end{array} & \begin{array}{l}\text { săam } \\ \text { três }\end{array} & \begin{array}{l}\text { prathêet } \\ \text { class-terra }\end{array} & \text { 'três países' }\end{array}$

Ao que parece, o uso de repetidores torna quase sem propósito o sistema de classificadores. Entretanto, gramaticalizados eles geralmente dão origem a classificadores como uma classe fechada ou semi-fechada de afixos de um numeral como ocorre, por exemplo, no Kilivila em que iga 'nome' é fonologicamente uma forma reduzida (encurtada) do 
repetidor yegila 'nome' em função classificadora (SENFT, 1996, apud AikHenvald, 2000).

Com respeito aos classificadores ligados aos numerais como afixos, inicialmente lembremos que, de modo geral, sufixos são mais freqüentes do que prefixos e isso pode justificar a preferência por sufixos como classificadores numéricos àqueles do tipo prefixos. Como prefixos encontramos classificadores numéricos na língua Teribe, da família Chibcha, como vemos, abaixo, nos exemplos de Quesada (2000):

$\begin{array}{llll}\begin{array}{l}\text { 12. domer } \\ \text { kl-ara }\end{array} & \mathrm{u} & \text { 'uma casa de homem (casa individual)' } \\ \text { class: animado-um } & \text { casa }\end{array}$

Afixos classificadores numéricos na forma de sufixos podem ser encontrados em línguas indígenas da América, como o Yucuna, da família Aruák do Norte (Schauer \& Schauer, 1978, apud Aikhenvald, 2000), a qual apresenta oito classificadores numéricos referentes à forma (esférico, cilíndrico, plano, lateral; simétrico; côncavo) e animado (humano e não-humano vivo), como ilustrado no exemplo abaixo:

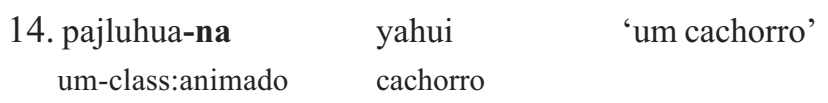

Outra língua que apresenta classificadores numéricos em forma de afixos é o japonês, que, segundo Denny (1979), possui várias centenas de classificadores ligados a numerais, embora os falantes normalmente usem apenas cerca de trinta e oito. No japonês há duas construções sintáticas nas quais os classificadores numéricos são usados. Na primeira delas é o sintagma nominal com o classificador numérico que envolve um conectivo ou partícula genitiva - no, básica e individualizada, como em (15). Já a outra construção, é chamada adverbial e envolve um sintagma com um verbo de ligação como no exemplo (16), a seguir:

$\begin{array}{cl}\text { 15. ni-daí-no } & \begin{array}{l}\text { kuruma } \\ \text { dois -class:veículo-ligamento } \\ \text { carro }\end{array}\end{array}$

SignóticA, v. 15, n. 2, p. 195-222, jul./dez. 2003 
$\begin{array}{cllll}\begin{array}{cll}\text { 16. enpitsu } \\ \text { lápis }\end{array} & \text { ga } & \text { san-bom } & \text { aru } & \text { 'há três lápis' } \\ \text { três-longo } & \text { haver } & \end{array}$

Retomando a questão da ordem nas construções de classificadores numéricos, já vimos que várias delas são possíveis. Entretanto, é sempre necessário que o classificador e o numeral permaneçam dentro do mesmo constituinte. No caso do japonês, percebemos duas possíveis ocorrências: o classificador numérico constituinte pode figurar em posição prenominal (com o conectivo no), como em (15), ou acompanhando o nome (sem o -no), como vemos nos exemplos seguintes:

17. ni-daí-no kuruma o kai-mashi-ta 'Ela/ele comprou dois carros' dois-num carro ACC comprar-masc-pass.

class:veículo

18. kuruma o ni-daí kai-mashi-ta 'Ela/ele comprou dois carros' carro ACC dois-num comprar-masc-pass.

class:veículo

Um outro tipo de classificador numérico seria o daqueles que podem ser fundidos a números e que ocorrem freqüentemente em línguas fusionantes e polissintéticas. Esse tipo de classificador pode também se ligar a um modificador diferentemente de um numeral. Em Nauru, língua da família Micronesiana, por exemplo, os classificadores numéricos fundem-se aos demonstrativos em um sintagma nominal de caráter numérico, como em n-aiquon-oe 'um destes aqui (inanimados)' e em n-airan-e 'um destes aqui (objetos planos)' conforme atestado por Kayser (1993, apud AiKhenvald, 2000).

Dentro dessa perspectiva, chama-nos também atenção o Yagua, língua polissintética da família Peba-Yagua que, segundo Payne \& Payne (1989), apresenta dois tipos de modificadores do sintagma nominal: os demonstrativos e os numerais. Eventualmente, a esses modificadores são afixados classificadores que, para os referidos autores, são do tipo nominal. ${ }^{4}$ Vejamos os dados a seguir:

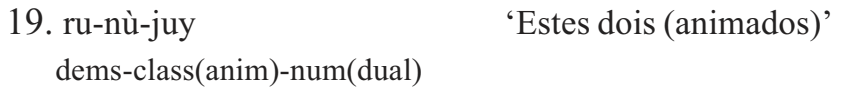


20. jiy-nù-juy

'Aqueles dois (animados)'

dems-class(anim)-num(dual)

Como mostram os dados, os demonstrativos jiy 'este' e ru 'aquele' recebem um sufixo classificador -nù, às vezes, seguido de outro sufixo de quantidade indicando o número (singular, dual, plural) do objeto ou ser referenciado pelo falante. Como podemos notar, esses dados indicam um comportamento semelhante entre o Yagua e o Nauru, o que nos leva a concluir que esse tipo de classificador que ocorre no Yagua é do tipo numérico.

Reforçamos essa hipótese com a análise do sistema numérico dessa língua também descrito brevemente por Payne (1986). Segundo essa autora, o sistema numérico do Yagua é decimal quartenário. Isso porque os numerais de 1 a 5 e também o 10 são os únicos que têm uma forma própria. Os numerais de 6 a 9 , por sua vez, são compostos pelas formas de 1 a 4 acrescentadas ao numeral 5, mais o sufixo -nijátaa (que significa 'um acima de'). Vejamos os exemplos, abaixo:

21. tá-juu-quiii 'um ovo' um-class: ovo-sg

22. dá-juu-juy 'dois ovos’ dois-class: ovos-dual

23. múmu-juu-miy 'três ovos' três-class: ovos-pl

24. day-juu-juyù 'quatro ovos' quatro-class: ovos-quatro

\section{5. vuyayújy-juu}

'dez ovos’

dez-class: ovos-dez

Pode ocorrer também de uma raiz numérica receber um classificador na forma de infixo às vezes com nominais plenos quando não existe um classificador específico ou com o classificador neutro -ra, como podemos ver no exemplo (26) abaixo, conforme Derbyshire \& Payne (1990): 
26. ray-tááryuy dá-ra-juy quínuu jazúcaru 'Eu comprei dois quilos de açúcar.' 1sg-comprar dois- kilo açúcar

class-num(dual)

Um terceiro caso de ocorrência dos classificadores numéricos a ser descrito é o dos que formam um constituinte com o nome principal ao invés do numeral. Entretanto, os únicos exemplos conhecidos desse sistema verificam-se em línguas Kegboid, como o Kana, em que os classificadores formam uma única palavra tanto fonológica quanto morfologicamente com o núcleo nominal, e não com o numeral. A ordem no sintagma nominal nessa língua é Numeral-Classificador-Núcleo Nominal, o que pode ser confirmado por critérios apontados por Ikoro (1994, apud AiKHENVALD, 2000), aqui transcritos:

a) uma regra de tom-reduzido sândi opera entre os componentes fonológicos de uma palavra, de modo que o primeiro componente nunca terá um tom elevado. Os classificadores nunca têm tons elevados, enquanto os numerais sim;

b) na língua Kana, o diminutivo proclítico $i$ é ligado ao classificador, e não ao substantivo, em uma construção Numeral-Classificador-Nome, como vemos nos exemplos:

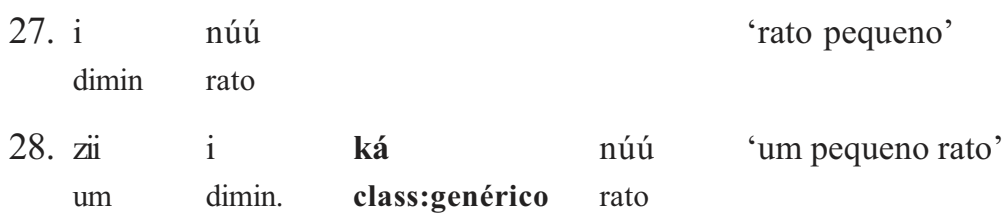

É interessante observar também que os tipos de classificadores numéricos apresentados anteriormente podem não ocorrer como única opção nas línguas, haja vista que em algumas delas mais de um tipo morfológico podem figurar simultaneamente, tal como apontaremos a seguir. 
Mais de um tipo morfológico de classificador numérico em línguas do mundo

Difícil, mas não impossível, é encontrar línguas que tenham mais de um tipo morfológico de classificador numérico. De fato, há apenas duas possibilidades de ocorrer esse fato: ou tipos diferentes de classificadores numéricos podem estar em distribuição complementar ou, então, ocorrer juntos e apresentarem propriedades diferentes. Vejamos alguns desses casos.

Sistemas diferentes de classificadores numéricos podem estar em distribuição complementar dependendo do numeral ou da semântica do classificador. Em Malto, língua da família Dravidiana do Sul (MAHAPATRA, 1979, apud AikHENVALD, 2000), os classificadores numéricos são lexemas independentes quando usados com o número três ou maiores do que ele. A ordem dentro de um sintagma nominal numérico é NumeralClassificador-Nome como vemos em (29) e com os números um ou dois, os classificadores para não-humanos ligam-se em forma de prefixos, e a estrutura sintagmática é Classificador-Numeral-Nome, tal como em (30), abaixo:

$\begin{array}{lll}\text { 29. tini maq } & \text { o:ydu } & \text { 'três vacas' } \\ \text { três class:inanim } & \text { vaca } & \\ \text { 30. maq-ond } & \text { o:ydu } & \text { 'uma vaca' } \\ \text { class:inanim-um } & \text { vaca } & \end{array}$

Em muitas línguas os classificadores para humanos (e/ou animados) têm formas diversas com números diferentes, como ocorre no Palikur, língua indígena brasileira da família Aruák, que possui riquíssima terminologia numérica. Segundo Green (1994), muitos dos numerais que indicam os algarismos de 1 a 199 apresentam afixos que modificam o nome ou o verbo a que se refere o numeral. Assim, encontra-se afixado à raiz de todo termo numérico um dos vinte classificadores numéricos, morfemas distintos e cujas categorias semânticas tratam de unidades individuais inteiras (termos numéricos acima do numeral que indica o 
algarismo 1 referente a uma unidade concreta), conjuntos (em que se incluem classes designadoras de plural, coleções e cesto cheio), frações (indicando os lados ou partes em que um objeto pode ser dividido), idéias abstratas (tais como doença, emprego, costume e qualquer ação específica) e séries (referentes a tempos, como dia e noite; também a respiração e outros eventos ou ações que são repetidos regularmente), respectivamente, ilustrados nos exemplos abaixo:

\begin{tabular}{|c|c|c|c|}
\hline \multicolumn{2}{|c|}{$\begin{array}{l}\text { 31. mpana-mku-a-kebyi } \\
\text { três- class:pl.fem.-N-unidades }\end{array}$} & & 'três canoas' \\
\hline $\begin{array}{l}\text { 32. paha-bru } \\
\text { um-class:grupo }\end{array}$ & & $\begin{array}{l}\text { eg } \\
\text { soas }\end{array}$ & 'um grupo de pessoas' \\
\hline $\begin{array}{l}\text { 33. pe-bkak } \\
\text { dois-class:lado }\end{array}$ & $\begin{array}{l}\mathrm{ka} \\
\mathrm{pa}\end{array}$ & & 'dois lados de papel' \\
\hline $\begin{array}{l}\text { 34. pi-ta-na } \\
\text { dois-class:abstrato-dois }\end{array}$ & $\begin{array}{l}\text { a-kebyi } \\
\text { N-unidade }\end{array}$ & $\begin{array}{l}\text { yuwit } \\
\text { palavra }\end{array}$ & 'duas palavras' \\
\hline $\begin{array}{l}\text { 35. paha- } i \\
\text { um-class:ser }\end{array}$ & & $\begin{array}{l}\text { nikanau } \\
\text { ego }\end{array}$ & 'um fôlego' \\
\hline
\end{tabular}

No Palikur, há uma particularidade em relação ao termo para o numeral que indica o algarismo 1 , o qual concorda em gênero com unidades animadas, pois no caso dos termos para os demais numerais não se vê essa concordância, como vemos nos exemplos:

$\begin{array}{lll}\text { 36. paha-p-ru } & \text { himano } & \text { 'uma moça' } \\ \text { um-class:anim-fem } & \text { moça } & \\ \text { 37. pi-ya-na } & \text { himano-pwiyo } & \text { 'duas moças' } \\ \text { dois-class:anim-dois } & \text { moça-pl } & \end{array}$

Além dessas características, vale ressaltar que na língua Palikur há um grande número de termos para dimensões formatos geométricos, tais como -u para 'redondo':
38.poho-u kapunma 'um maracujá'
um-class:redondo maracujá

210 CÂNdido, Gláucia Vieira. Propriedades de SISTEMAS de Classificadores... 
Outra propriedade da língua Palikur é que os termos numéricos podem vir acrescidos de nove flexões distintas que se referem a conceitos aritméticos como ordem numérica, adição, subtração, totalidade entre outros, o que ilustramos respectivamente com os exemplos:
39. gu-mapnam
ka atak
'A terceira (mulher) não foi'
fem.- três
neg. ir

40. nah iki pit-t paha-a-wa

arikna 'Vou te dar mais uma coisa'

eu dar você-para um- class:irreg.-adição coisa
41.msekw-e pehe-k-e parak 'Restou uma tábua'
ficar-comprido um-class:pl-resto tábua
42.pilatno bus-ip paha-twi-te 'O cacho de bananas está
banana estragar-est um-class:cacho-total

Do ponto de vista funcional, os classificadores numéricos no Palikur funcionam não somente como adjetivos, mas também como substantivos, pronomes, advérbios e verbos, apresentando todas as flexões gramaticais apropriadas para a função sintática que exercem. Não entraremos em minúcias sobre isso aqui, mas queremos salientar, entretanto, a idéia de que se um termo numérico apresenta uma variedade de classificadores, sufixos referentes a conceitos aritméticos, modificadores e sufixos sintáticos, o resultado disso só pode ser a existência de mais de duzentas formas de muitos termos numéricos, todas usadas cotidianamente pelos falantes do Palikur, como atesta Green (1994).

Enfim, o uso de grupos de classificadores bem diversos para números diferentes é relativamente comum, ainda que se observe em poucas línguas. Para concluirmos este tópico, descrevemos exemplos do To'aba'ita, língua Austronesiana, que usa um classificador opcional fa para 'pequenos objetos' com números abaixo de dez. Para o dez, há palavras diferentes e cuja seleção é determinada pela semântica do nome contado: taafulu, taafuli 'dez (geral)', qada 'dez (cocos)', akwala 'dez (pessoas, dentes de boto)', finta 'dez (raízes, frutas etc.)', lama 'dez (pássaros)', kobi 'dez (cordões de conchas moedas)', ai 'dez 
(recipientes de bambu cheios de castanhas canarium)'como ilustrado em Aikhenvald (2000).

Como todo evento lingüístico, naturalmente os classificadores numéricos não poderiam deixar de suscitar questionamentos, muitos dos quais já abordados em Aikhenvald (2000), Grinevald (2000), entre outros. Para fins deste estudo, retomaremos aqui algumas questões, especialmente, aquelas referentes à semântica, tal como veremos no próximo item.

\section{A NATUREZA DOS CLASSIFICADORES NUMÉRICOS: ALGUNS QUESTIONAMENTOS}

Um primeiro questionamento sobre os classificadores numéricos diz respeito à natureza semântica dos classificadores que, em princípio, podem ser de medida e seleção, haja vista a distinção entre os classificadores e as expressões quantificadoras ou termos de medida.

Comumente, se distinguem dois tipos de classificadores numéricos: os de seleção e os de medida. Segundo Lyons (1977, apud AikHEnvald, 2000), o classificador de seleção é aquele que individualiza tudo a que se refere em termos do tipo da entidade a que pertence, enquanto o classificador de medida individualiza algo em termos de quantidade. Os primeiros categorizam nomes em relação às suas propriedades inerentes, tais como material, forma, consistência; os últimos são usados para medir unidades de nomes contáveis e de massa. A escolha de um classificador de medida é condicionada por dois fatores: a) a quantidade ou medida de uma entidade e b) suas propriedades físicas permanentes ou, mais freqüentemente, temporárias. Encontramos exemplos disso no coreano (Lee, 1997, apud AikHENVALD, 2000):

$$
\begin{array}{rll}
\text { 43.makkeli } & \text { han } & \text { mal 'Uma medida de makkeli (arroz.vinho)' } \\
\text { arroz.vinho } & \text { um } & \begin{array}{l}
\text { mens. num.class: } \\
\text { arroz.vinho }
\end{array}
\end{array}
$$

Ao que tudo indica, o classificador de medida han é exclusivamente usado para medir arroz/vinho, referindo-se a uma xícara padronizada. 
Do ponto de vista semântico, também os classificadores de medida diferem dos de seleção. Tendo em vista que a escolha de um classificador de medida é quase sempre determinada pelo estado temporário de um objeto (sua quantidade, ou dentro da disposição em que ocorre) pode haver mais liberdade na escolha de um classificador de medida do que na de um de seleção. É o que ocorre, por exemplo, em Tzeltal, língua da família Maia, em que o nome lagrio 'tijolo' é usado com somente um classificador de seleção pech 'objeto retangular não-flexível'; mas quando contado pode ocorrer juntamente com vários classificadores de medida diferentes e que dependem da disposição: o classificador latz é usado em referência a um amontoado de tijolos, chol para tijolos alinhados, e bus para uma pilha de tijolos.

A distinção dos classificadores numéricos é outro problema a ser considerado, especialmente aquela entre os classificadores de medida e os quantificadores algumas vezes chamados 'termos de medida'. A esse respeito, Ahrens (1994, apud AikHENvald, 2000) observa que "os classificadores somente podem classificar sobre um grupo limitado e específico de nomes, enquanto os termos de medida podem ser usados como uma medida para uma ampla variedade de nomes". Quase toda língua, tenha classificadores numéricos ou não, tem quantificadores, dependendo da semântica do nome, como vemos, por exemplo, em inglês: much é usado com nomes não-contáveis, já many com contáveis. Outros exemplos seriam head ainda em inglês para 'cinco cabeças de gado' e em russo golova para 'cabeça' em sua equivalente pjatj golov skota; csepp 'gota' em Húngaro egy csepp méz 'uma gota de mel'. Naturalmente, essas expressões quantificadoras não podem ser classificadores numéricos pelas seguintes razões: a) elas não preenchem um espaço obrigatório em uma construção número-nome; b) ao contrário dos classificadores de medida, elas têm geralmente um significado léxico próprio; c) seus usos são freqüentemente relacionados à distinção entre os nomes contáveis e de massa, como por exemplo, 'mel', nome com referência de massa no Húngaro, que tem que ocorrer com um 
quantificador para que possa ser contado [*egy méz 'um mel' em vez de egy csepp méz 'uma gota de mel' que é agramatical]; d) elas são usadas em um tipo de construção que também é empregada em outros propósitos, ou seja, construções quantificadoras do tipo, em inglês, três cabeças de gado são na realidade um subtipo de construções de genitivo; finalmente, e) há um número restrito de tais palavras em uma língua não-classificável e elas também têm uma distribuição restrita.

Em algumas línguas, os classificadores numéricos podem ser usados também com sentido quantificador, como parte, tipo, metade, grupo, quarto, fatia etc. Assim, em Burmese napyó日îta-twê, que significa 'um cacho de bananas', o classificador -twê se refere a 'um cacho' de unidades. No restante do sintagma nominal está a propriedade 'banana' (Denny, 1986). Também em Baniwa de Içana, língua Aruák do Norte, classificadores quantificadores são usados como agentes de concordância com outros tipos de modificadores (AIKHENVALD, 1996 apud 2000). Nessa língua também os quantificadores estão numa classe fechada de palavras, os quais não levam classificadores nem mostram qualquer concordância com um nome a que se refere como vemos abaixo:

$\begin{array}{clc}\begin{array}{c}\text { 44. manupe } \\ \text { muitos }\end{array} & \begin{array}{l}\text { tsinu } \\ \text { cachorros }\end{array} & \text { 'muitos cachorros' } \\ \begin{array}{c}\text { 45.manupe } \\ \text { muitas }\end{array} & \begin{array}{l}\text { panti } \\ \text { casas }\end{array} & \text { 'muitas casas' } \\ & & \end{array}$

Difícil, contudo, é distinguir classificadores de quantificadores se eles ocuparem o mesmo espaço em um sintagma nominal, como parece ser o caso em várias línguas Austroasiáticas em que também verificamos diferenças significativas no uso de tais termos como classificadores numéricos e quantificadores. Aliás, a respeito disso, há controvérsias entre os teóricos. Burling (1965, apud AiKHENVALD, 2000), por exemplo, usa o termo 'classificador numérico' para se referir a todos os itens que ocorrem em um espaço adjacente a um numeral, como um termo de cobertura tanto para classificadores como para palavras de medida. Já

214 CÂNdido, Gláucia Vieira. Propriedades de SISTEMAS de Classificadores... 
Huffman (1970, apud AikHENVALD, 2000), refere-se a esse grupo de itens como 'especificadores'. Assim sendo, para se distinguir os classificadores numéricos dos quantificadores é preciso apelar para critérios de base específica de cada língua.

Critérios semânticos e pragmáticos para distinguir classificadores de expressões quantificadoras são também considerados. Afinal, enquanto os classificadores usam a unidade proveniente do nome contável, os quantificadores estabelecem a unidade a ser contada. Os classificadores categorizam os nomes em termos de tamanho, forma e animacidade e eles não provêem nenhuma informação sobre quantidade. As expressões quantificadoras têm menos restrições que os classificadores quanto ao tipo de nome em que eles podem ocorrer, isto é, em algumas línguas metade, por exemplo, é uma expressão quantificadora, e não um classificador numérico, desde que possa ser usada com qualquer nome contável.

Outra distinção entre os classificadores e expressões quantificadoras está normalmente ligada à subdivisão de nomes em contáveis e de massa (ou incontáveis). Afinal, como atesta Adams (1989 apud AikHENVALD), nomes de massa somente podem ser combinados com um numeral pelo uso de um quantificador, como no Comaltepeco Chinanteco, ${ }^{5}$ da família Otomangueana:

\begin{tabular}{|c|c|c|c|}
\hline 46. gém & $\operatorname{hi}^{\mathrm{L}}$ & & 'sete laranjas' \\
\hline sete & laranjas & & \\
\hline 47.tú ${ }^{\mathrm{M}}$ & má? ${ }^{\mathrm{L}}$ & $\mathrm{ma}^{\mathrm{L}} \mathrm{hi}^{\mathrm{L}}$ & 'duas folhas de papel' \\
\hline duas & class:folha/plano & papel & \\
\hline
\end{tabular}

O exemplo (46) mostra o nome contável 'laranja' em um sintagma numérico, e o (47) descreve um nome, 'papel', que nessa língua é não contável e portanto classificador de massa.

Outro critério de distinção entre as expressões quantificadoras e os classificadores refere-se aos atos de fala, pois os últimos, ao contrário das primeiras, podem ter usos pragmáticos. No Assamese, por exemplo, 
classificadores expressam definição-indefinição (BARZ \& DilLER, 1985, apud Aikhenvald, 2000), enquanto os classificadores em Vietnamese indicam definição e referenciação ao nome, o que, aliás, é interessante já que normalmente expressões quantificadoras não têm tal função.

Outras diferenças dizem respeito ao fato de que a ocorrência de classificadores em sintagmas numéricos não seja obrigatória. Em línguas como o Minangkabau os classificadores são freqüentemente omitidos na fala coloquial, o que não altera a semântica de um sintagma numérico. Em contrapartida, a omissão de uma expressão quantificadora afeta o sentido. Também na língua Khmer, classificadores são obrigatórios na forma padrão, mas não na fala informal; já expressões quantificadoras são 'obrigatórias' no sentido de que sua omissão altera o significado (AdAMs, 1986).

Além dos critérios semânticos e pragmáticos para distinguir classificadores de expressões quantificadoras, há também alguns critérios gramaticais nessa empreitada. A saber, os classificadores e expressões quantificadoras podem diferir na possibilidade de uso em outros ambientes de classificadores; em uso anafórico; e em concordância. Vejamos cada caso.

O comportamento morfossintático distinto dos classificadores e das expressões quantificadoras em Comaltepeco Chinanteco é expresso pelo fato de que as últimas concordam com o nome principal em gênero (animado versus inanimado), já com os classificadores tal fenômeno não ocorre.

No dialeto Nung, da língua Thai (SAul \& Wilson, 1980 apud Aikhenvald, 2000), somente os classificadores podem ser usados anaforicamente, ou seja, como 'substitutos' do nome principal, como em (48), abaixo. Já o uso anafórico de um classificador é ilustrado em (49), com óhng para 'humano', que, como notamos, está repetido e tem significado distributivo 'todo o mundo':

\begin{tabular}{|c|c|c|}
\hline 48. slám & áhn & boc \\
\hline três & class: genérico & flor \\
\hline
\end{tabular}

216 CÂNDIDO, Gláucia Vieira. PropriedAdEs de Sistemas de ClassificAdores... 


$$
\begin{array}{llll}
\text { 49.óhng óhng to ma chèu 'alguém } \\
\text { também pode olhar' } \\
\text { class: humano class: humano também vem olhar }
\end{array}
$$

Outras diferenças morfossintáticas interessantes entre as expressões quantificadoras e classificadores numéricos encontram-se no Akatek (Zavala, 1992 apud Aikhenvald). Por exemplo, um classificador numérico sufixado concorda com o nome principal em um sintagma numérico que não contenha uma expressão quantificadora, como ilustramos a seguir:

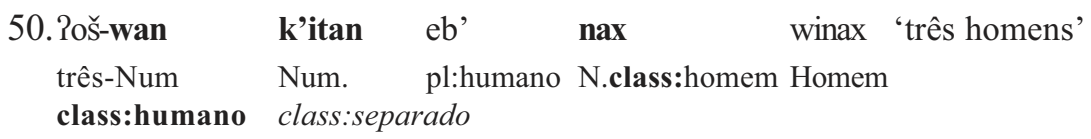

Se um sintagma numérico contiver uma expressão quantificadora, o classificador numérico afixado concordará com ela como vemos em (51), abaixo, em que o classificador -eb 'inanimado' se refere a tinan 'conglomerado':

51.?oš-eb' tinan eb' nax winax 'três grupos de homens' três-Num. quant: pl:hum. N.class:homem Homem class:inan conglomeração

Esses exemplos do Akatek demonstram claramente que enquanto um quantificador 'provê' uma unidade que é contável, o classificador categoriza esta unidade. Aliás, a conexão entre um quantificador e um nome não é tão rígida quanto aquela entre um classificador e um nome classificado, apesar da semelhança superficial entre os sintagmas classificadores e os de medida. Um verbo condicional, por exemplo, dây 'estar cheio de' ou um nome ru'ô' $i$ 'metade de' pode vir entre um quantificador e um nome, como observamos em (52), abaixo, o que não é possível em sintagmas com classificadores, já que essas formas têm que acompanhar o sintagma com classificador inteiramente, como vemos em (53):

$$
\begin{aligned}
& \text { 52.môt cân ru'õ'i chó 'um e um pouco de cachorros' } \\
& \text { um peso medida.de cachorro }
\end{aligned}
$$


$\begin{array}{cllll}\text { 53. môt } & \text { con } & \text { chó } & \text { ru'õ’i } \\ \text { um } & \text { class:animal } & \text { cachorro } & \text { medida } & \end{array}$

Evidentemente, as dificuldades em se discriminar os quantificadores dos classificadores podem estar no fato de que estes podem ser melhor visualizados como extremos de uma quantidade contínua. Como salienta Aikhenvald (2000), a quantidade e qualidade não são possivelmente classes semânticas discretas, mas sim 'polaridades de uma quantidade semântica contínua'. De modo semelhante aos classificadores de medida, os quantificadores ocorrem contíguos a numerais e a sua escolha também pode estar correlacionada às propriedades das unidades enumeradas. Por conseguinte, em algumas línguas as duas classes podem não ser distinguidas claramente.

Enfim, essas são apenas algumas das propriedades que parecem úteis na tarefa de distinguir os quantificadores dos classificadores. Certamente, critérios lingüísticos internos devem ser sempre usados para se estabelecer esta diferenciação.

\section{CONCLUSÃo}

No presente trabalho, enfocamos os sistemas de classificadores numéricos, isto é, de morfemas que combinam classificador e numeral modificando nomes em expressões que indicam quantidade. Como vimos, tais classificadores normalmente são escolhidos com base em critérios semânticos envolvendo categorias como: material, consistência, localização, quantidade, forma, tamanho, entre outros.

No que tange às propriedades tipológicas, vimos que os classificadores numéricos são mais recorrentes em línguas isolantes, mas por se comportarem também como afixos, ocorrem em línguas aglutinantes, polissintéticas e fusionantes. As línguas que possuem poucos numerais se apóiam em alguma forma dêitica para números mais significativos ou os emprestam de línguas próximas. 
Com respeito às realizações morfossintáticas, os classificadores podem ser lexemas independentes, afixos (sufixos mais do que prefixos) ligados a numerais e, finalmente, formadores de um constituinte com o nome principal ao invés do numeral.

Quanto à sintaxe de colocação e de acordo com Greenberg (apud AiKHENVALD, 2000), quatro são as ordens possíveis para os classificadores numéricos: a) [Num-Class]-N; b) N-[Num-Class]; c) [Class-Num]-N; e d) $\mathrm{N}$-[Class-Num].

Outro aspecto tratado neste estudo diz respeito ao fato de em algumas línguas figurarem simultaneamente mais de um tipo morfológico de classificadores, uma vez que, às vezes, tipos diferentes de classificadores podem estar em distribuição complementar ou, então, ocorrer juntos e apresentarem propriedades diferentes.

Outros pontos poderiam ter sido abordados, mas pela complexidade do tema a limitação se fez necessária. O nosso intuito, como dissemos no início do trabalho, foi apenas fazer uma revisão descritiva de algumas propriedades dos classificadores numéricos. Lembramos que outros aspectos desse e dos demais tipos de classificadores podem ser retomados com o respaldo de estudos bastante significativos como os de Allan (1977), Denny (1979), Grinevald (2000), Aikhenvald (2000), entre outros.

\section{AbSTRACT}

We present in this work a brief review description of some aspects of a very common type of classification system: the numerical classifiers. In this direction we present some basic properties of this kind of classifiers related with certain linguistics typology and we show the detailed description of these properties through examples collected from languages such as Japanese, Thai and in special some South and central Native American Languages such as Yagua (Peba-Yagua), Palikur (Aruak), Chibchan languages among others.

KEY wORDS: Linguistics, grammar, classification system, numerical classifiers. 


\section{NOTAS}

1. A esse respeito ver Grinevald (2000), que apresenta uma prévia de trabalhos tipológicos sobre o tema em questão.

2. As expressões "classificação nominal" e "classes nominais" podem suscitar algumas dúvidas. Contudo, Dixon (1986), estabelece a distinção entre essas expressões ao discutir algumas perspectivas tipológicas das mesmas. Assim, por classificação nominal estamos entendendo uma categoria gramatical (em que se incluem tipos de sistemas de gêneros, por exemplo), bem como um fenômeno léxico-sintático denominado classificadores nominais (em que se incluem os classificadores numéricos). Por outro lado, as classes nominais constituem um sistema gramatical obrigatório, em que cada nome escolhe uma classe dentre um pequeno número de possibilidades. Classes nominais podem ser marcadas por prefixos no nome e usualmente também em outros constituintes: no sintagma nominal ou na sentença e que mostre concordância com ele, como no Bantu; em artigo obrigatório, como no Francês e no Alemão; ou em um sufixo flexional que mostre portmanteau de caso e classe nominal como no Latim.

3. Abreviações: anim: animado/animação; class: classificador; dems: demonstrativo; dimin: diminutivo; fem: feminino; gen: gênero; inanim: inanimado; masc: masculino; N: nome; Num/num: numeral/numérico; pl: plural; sg: singular.

4. A respeito de terminologias, lembramos que há uma grande diversidade no tratamento dos sistemas de classificadores numéricos. Grinevald (2000) chama atenção para o fato de o termo "numeral" estar sendo referido por meio de outros termos tais como "numerativo", "número" e até mesmo "nome", respectivamente, por Becher, Sanches e Erbaugh (1986, 1973 e 1986, apud GRINEVALD, 2000).

5. As iniciais $\mathrm{Me} \mathrm{L}$ indicam tons médio e baixo, respectivamente.

\section{REFERÊNCIAS}

AdAms, K. L. Numeral classifiers in austroasiatic. In: CRAIG, C. (Ed.) Noun classes and categorization. Typological studies in language. Amsterdam/Philadelphia: John Benjamins Publishing Company, 1986. 
Adams, K. L.; Conklin, N. F. Toward a theory of natural classification. Papers from the Annual Regional Meeting of the Chicago Linguistic Society, v. 9, p. 1-10, 1973.

Aikhenvald, A. Y. Classifiers: a typology of noun categorization devices. New York: Oxford, 2000. 1994.

Classifiers in Tariana. Anthropological linguistics, v. 34, p. 407-465,

Allan, K. Classifiers. Language, v. 53, n. 2, p. 285-311, 1977.

Barnes, J. Classifiers in Tuyuca. In: PAyne, D. L. Amazonian linguistics. Studies in lowland south american languages. Austin: University of Texas Press, 1990.

Croft, W. Semantic universals in classifier systems. Word, v. 45, n. 2, p. 145-171, 1994.

Denny, J. P. What are noun classifiers good for? In: Mufwene, Salikoko S.; Walker, Carol A.; Steever, Sanford B. Papers from the $12^{\text {th }}$ regional meeting. Chicago Linguistic Society, 1976. p. 122-32.

Semantic analysis of selected Japanese numeral classifiers for units. Linguistics, v. 17, p. 317-35, 1979.

. The semantic role of noun classifiers. In: CRAIG, C. (Ed.) Noun classes and categorization. Typological studies in language. Amsterdam/Philadelphia: John Benjamins Publishing Company, 1986.

Derbyshire, D. C.; Payne, D. L. Noun classification systems of Amazonian languages. In: PAYNe, D. L. Amazonian linguistics. Studies in lowland south american languages. Austin: University of Texas Press, 1990.

DixON, R. M. W. Noun classes and noun classification in typological perspective. In: Craig, C. (Ed.) Noun classes and categorization. Typological studies in language. Amsterdam/Philadelphia: John Benjamins Publishing Company, 1986.

Gandour, J.; Buckingham, H.; Dardarananda, R. The dissolution of numeral classifiers in Thai. Linguistics, v. 23, p. 547-66, 1985.

Green, D. O sistema numérico na língua Palikur. Boletim do Museu Paraense Emílio Goeldi. Belém: MPEG, v. 10, p. 261-303, 1996.

Diferenças entre termos numéricos em algumas línguas indígenas do Brasil. Boletim do Museu Paraense Emílio Goeldi. Belém: MPEG, v. 13, n. 2, 1997.

SignóticA, v. 15, n. 2, p. 195-222, jul./dez. 2003 
Grinevald, C. A morphossyntactic typology of classifiers. In: Senft, G. (Org.). Systems of nominal classification. New York: Cambridge University Press, 2000.

Hass, M. R. The use of numeral classifiers in Thai. Language, v. 18, p. 201-205, 1942.

Hundius, H.; Kölver, U. Sintax and semantics of numeral classifiers in Thai. Studies in Language, v. 7, p. 165-214, 1983.

Payne, D. L. Noun classification in Yagua. In: Craig, C. (Ed.). Noun classes and categorization. Typological studies in language. Amsterdam/Philadelphia: John Benjamins Publishing Company, 1986.

Payne, D. L.; Payne, T. E. Yagua. In: Derbyshire, D. C. \& Pullum, G. K. (Eds.). Handbook of Amazonian Languages. Berlin/New York: Monton de Gruyter, 1990.

PeñA, E. M. Diccionario Cabécar-Español/Español-Cabécar. San José: Editorial de la Universidad de Costa Rica, 1989.

QuESADA, J. D. A grammar of Teribe. Berlim: Lincom Studies in Native American Linguistics, 36. 2000. 